14,11

\title{
Источники и приемники терагерцевого излучения на основе микрорезонаторов, встроенных в краевые каналы кремниевых наносандвичей
}

\author{
(C) Н.Т. Баграев, ${ }^{1,2}$ П.А. Головин, ${ }^{1,2}$ Л.Е. Клячкин, ${ }^{1}$ А.М. Маляренко, ${ }^{1}$ А.П. Преснухина, ${ }^{3}$ Н.И. Руль, ${ }^{1,2}$ \\ A.C. Реуков, ${ }^{3}$ B.С. Хромов ${ }^{1}$ \\ ${ }^{1}$ Физико-технический институт им. А.Ф. Иофффе РАН, \\ 194021 Санкт-Петербург, Россия \\ ${ }^{2}$ Санкт-Петербургский политехнический университет Петра Великого, \\ 195251 Санкт-Петербург, Россия \\ ${ }^{3}$ Национальный медицинский исследовательский центр им. В.А. Алмазова, \\ 197341 Санкт-Петербург, Россия \\ e-mail: bagraev@mail.ioffe.ru
}

Поступило в Редакцию 16 января 2020г.

В окончательной редакции 21 февраля 2020 г.

Принято к публикации 3 марта 2020 г.

В последние 30 лет проявляется большой интерес к использованию терагерцевого (THz) излучения в различных сферах, таких как системы безопасности, связь, спектроскопия. Кроме того, ТНz-излучение получает все большее применение в практической медицине, в частности, продемонстрированы возможности влияния THz-излучения на реакции метаболизма в сочетании с управлением важнейшими биохимическими процессами в организме человека. Это, в свою очередь, стимулировало разработку компактных источников и приемников $\mathrm{THz}-$ и гигагерцевого $(\mathrm{GHz})$ излучения электромагнитного спектра на основе развития кремниевой опто- и наноэлектроники. Были созданы кремниевые излучатели с возможностью управления THzи GHz-частотной модуляцией, что позволило применить их для эффективной терапии демиелинизирующих заболеваний центральной нервной системы.

Ключевые слова: кремниевый наносандвич, терагерцевое излучение, микрорезонаторы, терапия заболеваний центральной нервной системы.

DOI: $10.21883 /$ JTF.2020.10.49797.19-20

\section{Введение}

Диапазон терагерцевого (THz) излучения охватывает частоты от $100 \mathrm{GHz}$ до $30 \mathrm{THz}$, что эквивалентно длинам волн $3 \mathrm{~mm}-10 \mu \mathrm{m}$. В этот диапазон входит часть микроволнового спектра, а так же средний и дальний ИКдиапазоны (рис. 1,a). Следует отметить, что в спектре пропускания земной атмосферы присутствует THz-щель, которая демонстрирует практически полное поглощение THz-излучения (рис. $1, b)$.

Преимущество THz-излучения заключается в том, что оно не имеет ионизационной опасности для биотканей вследствие достаточно малой энергии. Более того, THzизлучение мощностью десятки-сотни $\mathrm{nW}$ эффективно воздействует на ход важнейших биохимических реакций $[1,2]$. К особенностям данного излучения стоит также отнести беспрепятственное прохождение сквозь костную ткань, возбуждение вращательных и колебательных мод белков, соответствие частоте осцилляций связей внутри белковых мод [1].

THz-излучение способно углубляться в кожный покров до нескольких сантиметров, хотя при этом и ослабляется на порядки. Однако его эффективность сохраняется благодаря низкому порогу воздействия на ход важнейших биохимических реакций $[1,2]$. Тем не ме- нее значительная часть важного для жизнедеятельности человека солнечного излучения, включая THz-диапазон, как отмечено выше, поглощается земной атмосферой. Поэтому особое значение приобретает разработка и создание искусственных источников и приемников $\mathrm{THz}-$ излучения.

Исходя из вышесказанного, заслуживает внимания

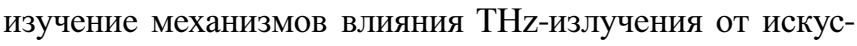
ственных компактных источников на процессы энергообмена в клетках, которые основаны на биохимических реакциях катаболизма и анаболизма.

В анаболических реакциях происходит синтез необходимых клетке биохимических веществ (белков, углеводов, жирных кислот и т.д.), а в реакциях катаболизма разложение сложных веществ, поступивших в организм с пищей. Было обнаружено, что THz-излучение с энергией 0.02)_0.3 eV приводит к активации процессов анаболизма и транспорта в клетке. В частности, усиливаются синтез белка, захват кислорода ионами железа в мио- и гемоглобине, перенос ионов металлов через клеточные мембраны [2].

Как известно, синтез сложных биомолекул сам по себе термодинамически невыгоден: изменение свободной энергии Гиббса $\Delta G$ в таких реакциях положительно. По- 
Frequency, $\mathrm{GHz}$

$a$
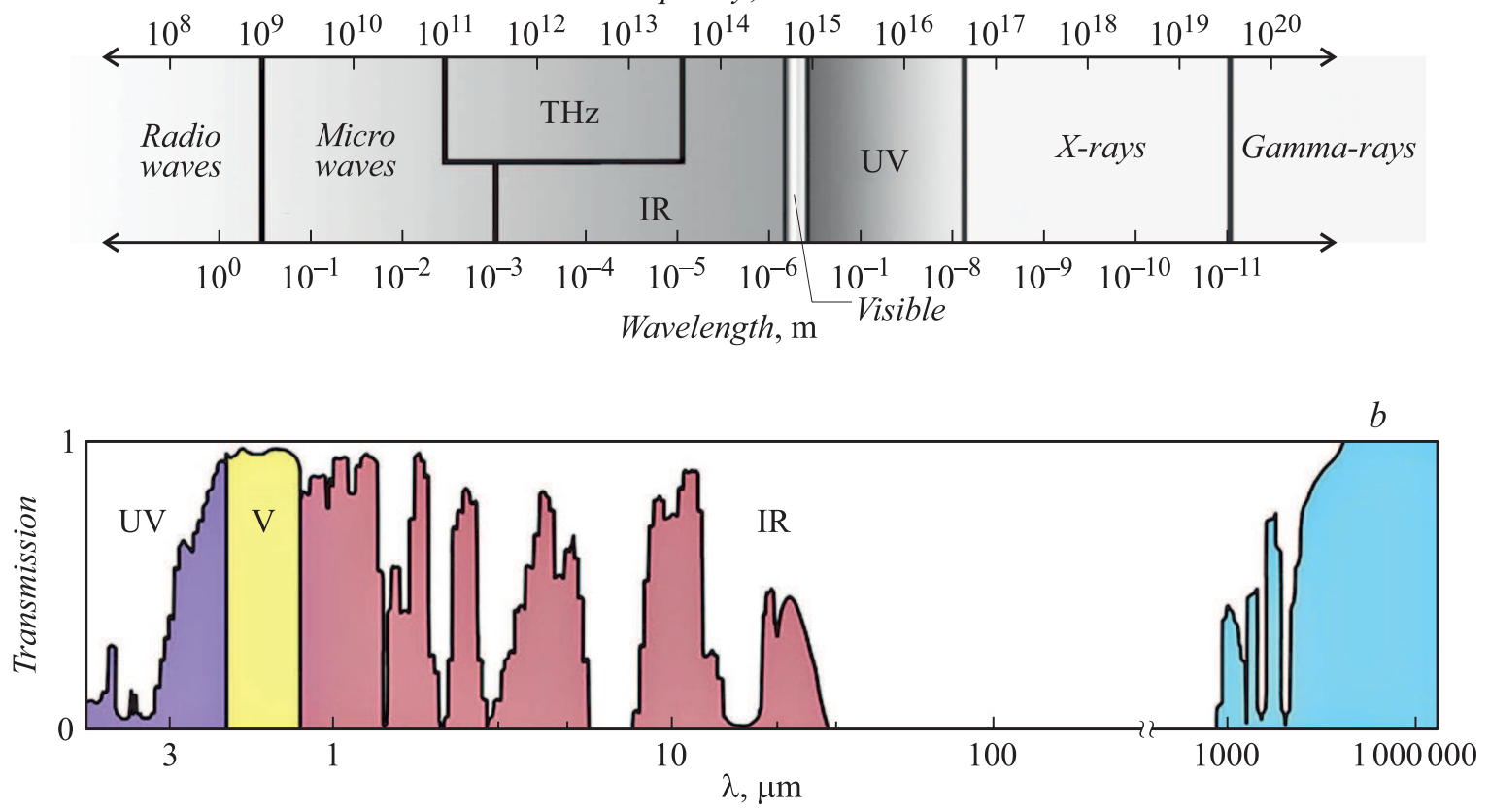

Рис. 1. $a-$ спектр электромагнитного излучения. $b-$ спектр пропускания земной атмосферы.<smiles>CO[PH2+]OP(=O)(O)OP(=O)(O)OP(=O)(O)OC1CC2CCC21</smiles>

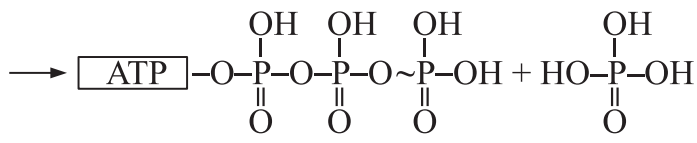

Рис. 2. Химическая реакция гидролиза АТФ.

этому их протекание должно сопровождаться какими-то выгодными процессами с большим отрицательным $\Delta G$. Такой реакцией в большинстве случаев является гидролиз аденозинтрифосфата (АТФ) или гуанозинтрифосфата (ГТФ) [3]. АТФ представляет собой этерифицированный трифосфорной кислотой по ОН-группе рибозы нуклеид аденин и может быть гидролизован с образованием аденозиндифосфата (АДФ) и неорганического фосфата $\Phi$ (рис. 2): АТФ $+\mathrm{H}_{2} \mathrm{O}=\mathrm{AД} \Phi+\Phi$. Эта реакция протекает с выходом большого количества энергии $(0.54 \mathrm{eV})$. При присоединении фосфатной группы за счет солнечной (фотосинтез) или химической энергии АДФ может быть вновь превращен в АТФ.

ГТФ, необходимый, например, при биосинтезе белка и его транспорте через мембрану, образуется из АТФ и ГМФ (гуанозинмонофосфат) в две стадии, где участвует гуанозиндифосфат (ГДФ): ГМФ + АТФ = ГДФ + АДФ; $\Gamma Д \Phi+$ АТФ $=$ ГТФ + АДФ. Следует отметить, что эта реакция имеет важнейшее значение для транспорта белков между мембранами внутри клетки, а также вне ее.
На начальной стадии этого процесса белки, формирующиеся в эндоплазматической сети, сортируются и помещаются в пузырьки-контейнеры, находящиеся на внутренних мембранах [3]. В процессе транспортировки этот пузырек отпочковывается и переносится внутри клетки, после чего пристает к нужной мембране и сливается с ней. Важно, что транспорт белков осуществляется благодаря наличию на поверхности пузырьков молекул ГТФ, которые возникают под действием фермента (инсулина), стимулирующего присоединение фосфатной группы к ГДФ [3]. В процессе транспортировки пузырька ГТФ конвертируется в ГДФ, что сопровождается выбросом одного из фосфатов, из-за чего выделяется энергия для транспортировки пузырьков в цитоплазме ([3], Rothman J.E., Нобелевская премия по медицине за 2013 г. совместно с Schekman R.W., Südhof T.C.).

В случае отсутствия фермента транспорт белков между мембранами внутри и вне клетки может стимулироваться с помощью THz-излучения, что, в частности, проявляется в уменьшении содержания глюкозы и увеличении содержания гемоглобина в крови [4].

Возможно, стимулирование THz-излучением реакций метаболизма при недостатке ферментов показывает, что энергия квантов может использоваться клеткой вместо энергии гидролиза АТФ. Такое предположение было высказано в начале 80-х годов в связи с тем, что точки, в которых происходит гидролиз АТФ и потребление его энергии, зачастую разделены расстояниями, значительно превышающими межатомные. Причем переносчиком энергии гидролиза молекул АТФ вдоль альфа- 


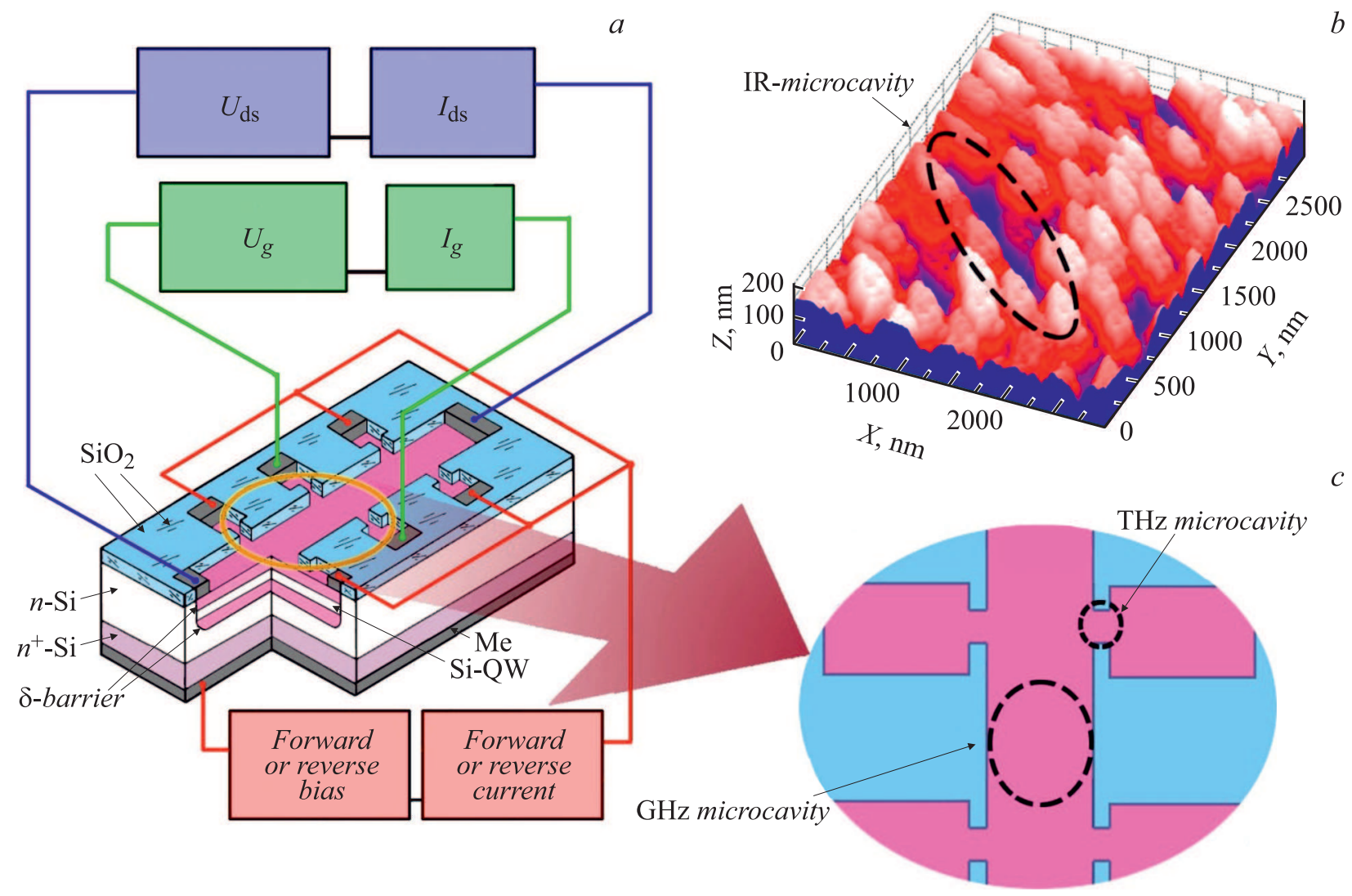

Рис. 3. ТНz-излучатель, выполненный в геометрии холловского мостика на СККЯ p-типа проводимости, ограниченной дельтабарьерами на поверхности монокристаллического кремния $n$-типа $(a)$ со встроенными микрорезонаторами, настроенными на длины волн из спектрального THz-диапазона биохимических реакций; фрагмент СТМ изображения $(b)$ показывает микрорезонатор для стимулирования ИК-излучением реакций в гемоглобине; при варьировании расположением и размерами контактов, предусматриваются возможности для реализации микроволновых резонаторов $(c)$ для модуляции THz-излучения в THz- и GHz-частотных диапазонах.

спиральных белковых молекул, возможно, является солитон - сохраняющая форму уединенная волна [5].

Следует отметить, что время жизни солитона напрямую зависит от числа пептидных групп, вовлеченных в его формирование при оптическом облучении, например в спектральном диапазоне возбуждения водородной связи $(0.165-0.3 \mathrm{eV}$, что соответствует интервалу длин волн ИК-диапазона 4-7.5 $\mu \mathrm{m}$, внутри которого находится значение энергии колебаний линейных молекул). Так, в случае участия трех пептидных групп время жизни солитона равно $0.5 \mathrm{~s}$, при участии шести пептидных групп $41 \mathrm{~s}$. При вовлечении девяти пептидных групп, общий размер которых гораздо меньше диаметра оптического луча, время жизни солитона, соответствующего колебаниям в альфа-спиральных белковых молекулах при оптическом возбуждении водородной связи, составляет $22.5 \mathrm{~min}$, что практически совпадает с временем THzстимулирования уменьшения глюкозы и со временем соответствующего роста гемоглобина в крови $[4,5]$.

Вышесказанное позволяет предположить, что воздействие THz-излучения на клетки заключается в том, что кванты внешнего излучения способны возбуждать солитоны вдоль альфа-спиральных белковых молекул, энергия которых может использоваться в процессе синтеза белков взамен энергии АТФ.

\section{1. Техническая реализация источников THz-излучения c GHz-модуляцией}

Задача получения THz-излучения, модулированного в гигагерцевом $(\mathrm{GHz})$ диапазоне, была успешно решена с помощью твердотельных излучателей, изготовленных с использованием кремниевой нанотехнологии на основе монокристаллического кремния. Излучатели представляют собой управляемые генераторы дальнего ИК-диапазона длин волн от 1 до $700 \mu \mathrm{m}$ c THz- и GHz-модуляцией во всем диапазоне спектра излучения.

Решение этой задачи стало возможным благодаря реализации квантоворазмерных $p-n$-переходов на поверхности монокристаллического кремния с глубиной от 20 до $30 \mathrm{~nm}$, которые содержат каскады сверхузких кремниевых квантовых ям (СККЯ) шириной $2 \mathrm{~nm}$, ограниченных дельта-барьерами, состоящими из дипольных центров бора с отрицательной корреляционной энергией 

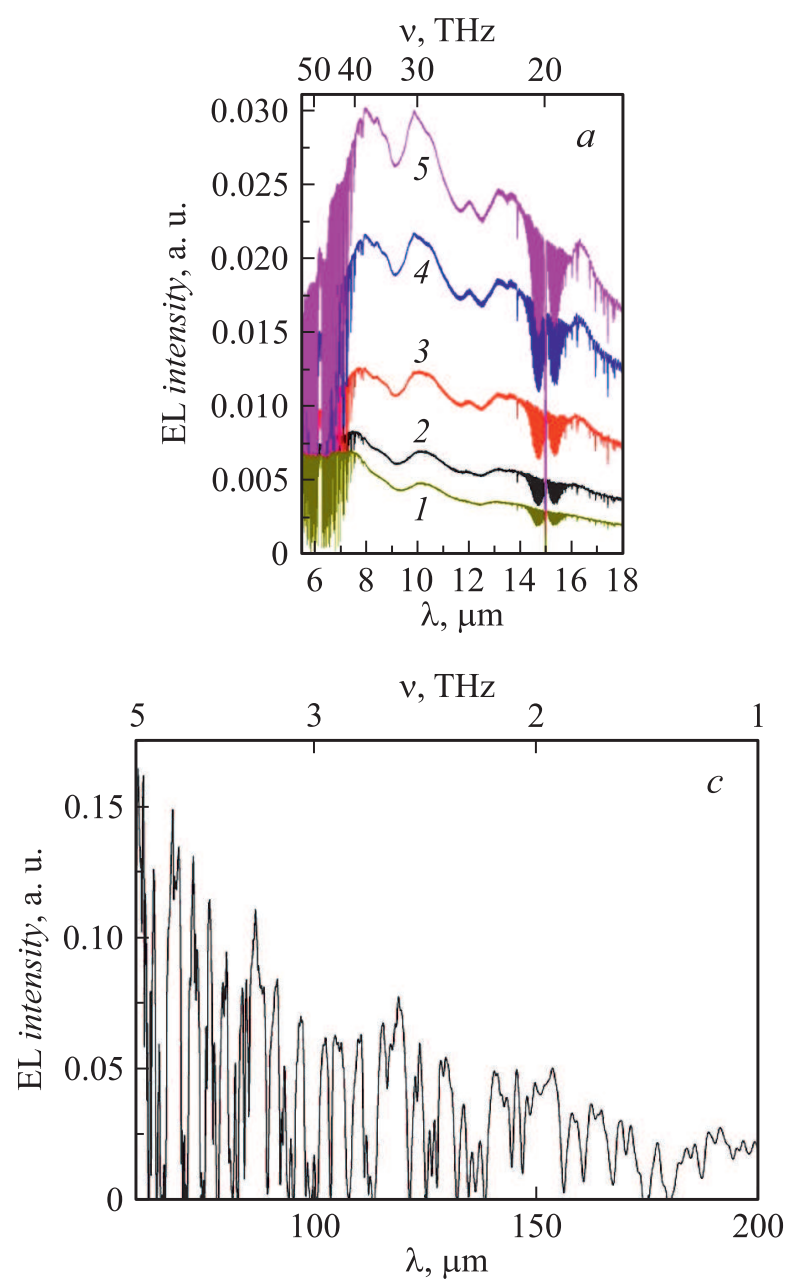
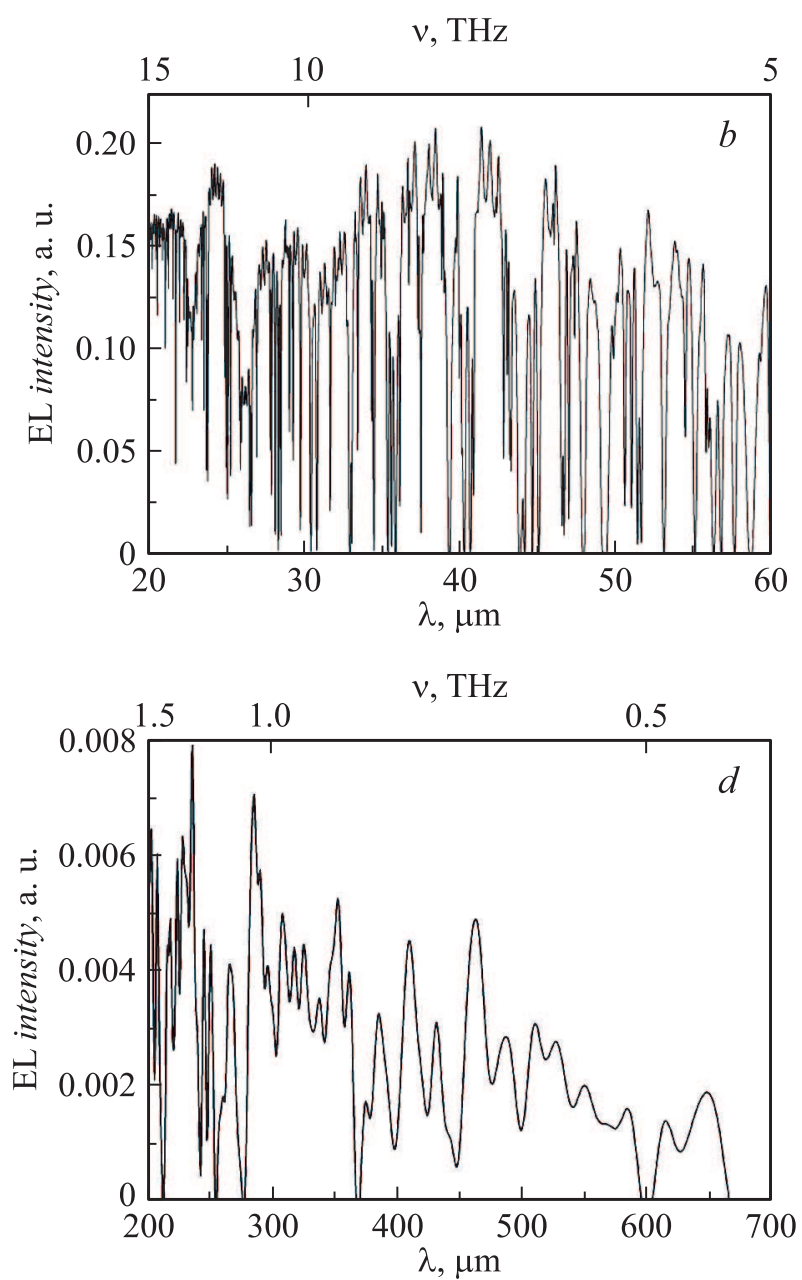

Pис. 4. Спектры электролюминесценции кремниевого THz-излучателя в условиях протекания продольного тока исток-сток, $I_{d s}$ : в ближнем $(a)$, среднем $(b)$ и дальнем ИК $(c)$ диапазонах, а также в микроволновой области $(d)$ электромагнитного спектра излучения. $a-1-I_{\mathrm{ds}}=0 ; 2-20 ; 3-30 ; 4-40 ; 5-60 \mathrm{~mA} . T=300 \mathrm{~K}$.

(рис. 3) [6]. В процессе протекания продольного тока через структуру, выполненную в холловской геометрии, возникает интенсивное ИК- и ТНz-излучение, идентифицированное с помощью ИК-Фурье спектрометра BrukerPhysik VERTEX 70 FT-IR (рис. 4,5). Спектральная характеристика излучения отражает резонансный характер оптических переходов между уровнями размерного квантования (рис. 4). Полученные спектры также демонстрируют наличие интерференции и одиночных линий в терагерцевом частотном диапазоне, причtм обнаруженная модуляция соответствует геометрическим параметрам краевых каналов (рис. 4,5). Кроме того, как показали проведенные исследования макроскопических квантовых явлений при высоких температурах вплоть до комнатной, основной вклад в THz-излучение обусловлен доминирующей ролью квантового эффекта Фарадея $[4,6]$.

Кроме того, два одинаковых образца могут составить пару источник-приемник THz-излучения. При этом отклик приемника идентифицируется в реальном времени. На рис. 6 показано изменение продольного напряжения образца, использованного в качестве приемника, которое демонстрирует отклик на THz-излучение аналогичного образца, используемого в качестве источника. Параметры данного отклика взаимосвязаны со структурой краевых каналов СККЯ и, по-видимому, обусловлены вкладом квантового эффекта Фарадея, а также излучательными переходами в системе центров с отрицательной корреляционной энергией. Однако вопрос о доминировании того или иного механизма в генерации

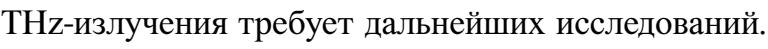

Характеристики THz-излучения из квантово-размерных $p-n$-переходов могут контролироваться в ходе варьирования режимов планарной кремниевой технологии, которые позволяют получить внутри краевых каналов СККЯ системы фрактальных микрорезонаторов (рис. 3,5), настроенных на характерные длины волн THz-излучения, что делает возможным многократное усиление его интенсивности. Кроме того, разработанная нанотехнология получения дельта-барьеров, ограничивающих СККЯ, делает возможным введение непосред- 

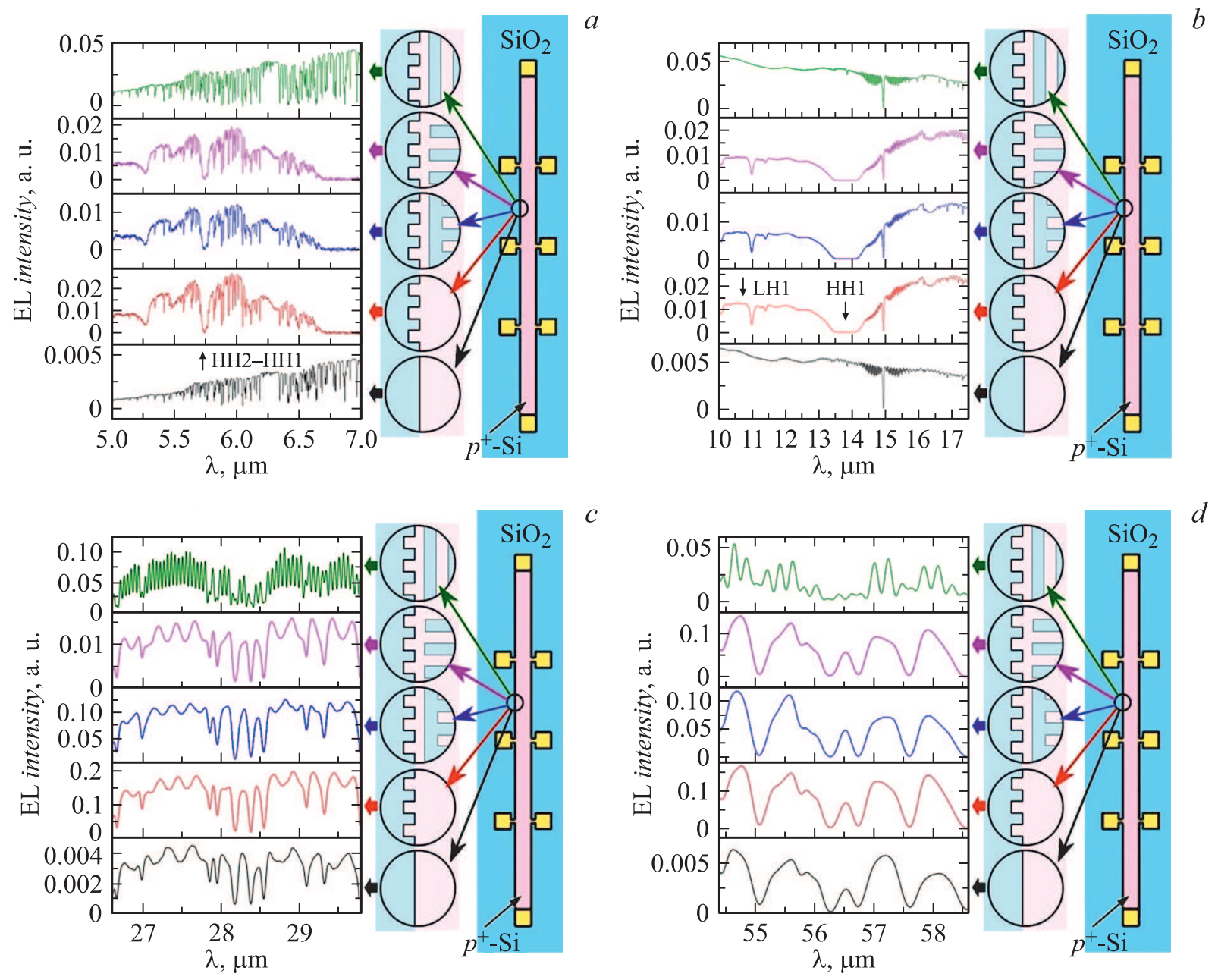

Рис. 5. Модулированные спектры электролюминесценции кремниевого THz-излучателя, изготовленного в холловской геометрии, в условиях протекания продольного тока исток-сток, $I_{t e x t d s}$ : в ближнем $(a)$, среднем $(b)$ и дальнем ИК $(c, d)$. Форма и модуляция THz-спектров контролируются введением продольных и поперечных микрорезонаторов типа Фабри-Перо, встроенных в краевые каналы кремниевой квантовой ямы (см. на вставках увеличенные участки различных версий краевого канала излучателя). В отсутствие модуляции наблюдаются особенности, связанные с позициями уровней размерного квантования в СККЯ $(b)$. $T=300 \mathrm{~K}, I_{\mathrm{ds}}=30 \mathrm{~mA}$.

ственно в краевые каналы продольных и поперечных микрорезонаторов типа Фабри-Перо, тем самым создавая условия для амплитудной и частотной модуляции THz-излучения (рис. 5).

\section{2. Применение THz-излучения c GHz-модуляцией для лечения пациентов с ишемическим инсультом}

Среди всей аппаратуры, использующей механизм THz-излучения, стоит выделить „ИК-диполь“ созданный в 1990-х годах [4]. В его основу входит кремниевая планарная технология. Данный прибор успешно внедрен в НМИЦ ФГБУ им. В.А. Алмазова и служит для терапии ангеопатии при сахарном диабете, трофических язв и пролежней, неосложненной и хронической язв желудка и двенадцатиперстной кишки, артрозов, пародонтозов, термических и радиационных поражений кожного покрова, рубцовых постхирургических деформаций [4]. Но наиболее важным является его свойство воздействовать на калиево-натриевый насос и лимфатическую систему в целом. Под действием THz-излучения на лимфатическую систему реакция АТФ + ГДФ $=$ ГТФ + АДФ сопровождается рождением солитона, что в свою очередь приводит к открытию лимфатической системы с последующим удалением продуктов распада белков и ферментов, образованных в результате ишемического инсульта. Следует отметить, что картина лимфатической сети достаточно хорошо согласуется с известной сетью акупунктуры, а также с установленными схемами передачи нервного импульса.

В последние годы была проделана большая работа по поиску лимфатической системы головного мозга. При поиске шлюзов Т-клеток в мозговых оболочках А. Луво с 


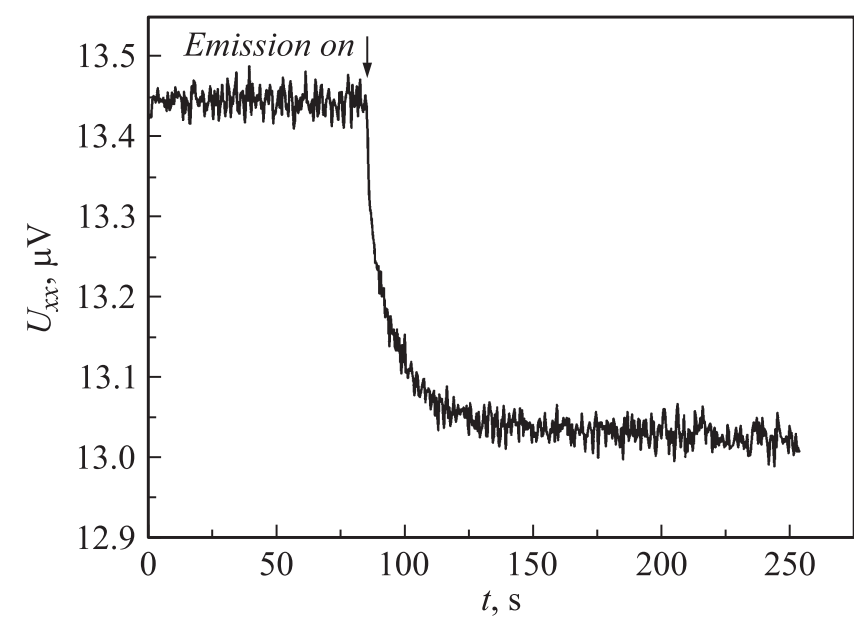

Рис. 6. Зависимость продольного напряжения образца (квантово-размерного $p-n$-перехода) в рамках холловской гео-

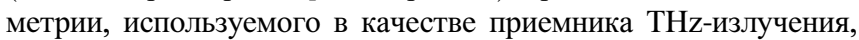
которая отражает отклик на THz-излучение аналогичного образца, используемого в качестве источника. Стабилизированный продольный ток исток-сток приемника $I_{\mathrm{ds}}=10 \mathrm{nA}$. THzизлучение индуцировалось в условиях пропускания продольного тока через излучатель $I_{\mathrm{ds}}=30 \mathrm{~mA}, T=300 \mathrm{~K}$.

коллегами обнаружили функциональные лимфатические сосуды, выстилающие дуральные пазухи [7,8]. Эти структуры отражают все молекулярные запасы лимфатических эндотелиальных клеток и способны переносить как жидкости, так и иммунные клетки из спинномозговой жидкости, а также связаны с глубокими шейными лимфатическими узлами. Уникальное местоположение этих сосудов, возможно, препятствовало их обнаружению на сегодняшний день, тем самым внося вклад в давнюю концепцию отсутствия лимфатической вазоматерии в центральной нервной системе (ЦНС). Открытие лимфатической системы ЦНС требует повторной оценки основных состояний в области нейроиммунологии, в результате которой проводится этиология нейровоспалительных и нейродегенеративных заболеваний, связанных с дисфункцией иммунной системы $[7,8]$.

С помощью иммуногистохимии и флуоресцентной микроскопии группе А. Луво удалось идентифицировать лимфатическую систему головы, найти характеристические длины, а также определить прогрессию болезни Альцгеймера [8]. Анализ результатов, полученных А. Луво, позволил найти характеристические размеры лимфатической системы головы, которые определяют размеры микрорезонаторов, усиливающих THz- и GHz-возбуждение олигонуклеотидов при формировании солитонов в процессе облучения соответствующих областей головы с помощью кремниевого THz-излучателя. Обнаружено, что размеры лимфатических сосудов (в частности, для верхнего сагиттального синуса) коррелируют с длинами волн THz-диапазона. Для расчета использовалась формула для резонатора Фабри-Перо: $d=\frac{\lambda}{2 n}$, где $n-$ коэффициент преломления (1 для воды и 3.4 для кремния). Следует отметить, что наблюдается размерная корреляция между лимфатической и акупунктурной сетками. Таким образом, можно расширить использование THz-излучения в медицине. Предполагается что THz-излучение будет воздействовать на лимфатическую систему головы, тем самым оказывая терапевтический эффект для экспресс-лечения инсультов и сопутствующих заболеваний, поскольку THz- и GHz-облучение олигонуклеотидов способствует увеличению эластичности лимфатической системы головы и соответствующему эффективному удалению продуктов распада белковых соединений. Таким образом, разработка THz- и GHz-оборудования позволит сделать еще один шаг в сторону развития персонифицированной медицины.

Исследования в данном направлении проводились в Национальном медицинском исследовательском центре им. В.А. Алмазова на протяжении четырех лет (с 2011 по 2015 гг). Под наблюдением находился 61 пациент с ишемическим инсультом (ИИ) в возрасте от 18 до 86 лет (средний возраст $59 \pm 1.4$ ) из них 24 женщины и 36 мужчин, которые были разделены на две группы: в I группу вошли 30 человек (средний возраст $61 \pm 2.1$ ) и во II группу - 31 пациент (средний возраст $58 \pm 1$ ).

Истории болезни в обеих группах на первом стационарном этапе подбирались таким образом, чтобы эти группы по четырем показателям, а именно основное заболевание, основное сопутствующее заболевание, пол и возраст, соответствовали друг другу. У 15 больных I группы зона ИИ была в бассейне правой средней мозговой артерии, у одиннадцати - левой, и по одному больному с локализацией очага в бассейнах и правой, и левой средних мозговых артерий, правой средней и правой задней мозговых артерий, правой средней и левой задней мозговых артерий, правой средней мозговой артерии и вертебробазиллярной системы. Локализация очага поражения во II группе была практически аналогичной.

Во время пребывания в отделении реанимации отмечались различные клинические проблемы, разрешить которые в приемлемые сроки обычно применяемыми методами в рамках отечественных и международных стандартов лечения больных с ИИ не удавалось. К таким проблемам относились рефрактерные к проводимому лечению коматозное состояние, судорожный синдром, тетраплегия, угрожающие жизни нарушения сердечного ритма, гипертермия и ряд других.

Для решения этих проблем пациентам I группы дополнительно к фармакотерапии проводилось транскраниальное воздействие инфракрасным излучением, модулированным THz-частотами аппаратом ИК-Диполь (ООО „Дипольные структуры“, Санкт-Петербург). Спектр излучения аппарата $1-56 \mu \mathrm{m} \mathrm{c} \mathrm{THz-модуляцией}$ $0.086-7.5 \mu \mathrm{m}$. Мощность излучения $30 \mathrm{~mW}$. Плотность потока излучения $2.4 \mathrm{~mW} / \mathrm{cm}^{2}$. Площадь основания излучателя $79 \mathrm{~cm}^{2}$. Излучатель устанавливался на область темени в проекции акупунктурной точки Бай-Хуэй (VG-20) независимо от локализации зоны поражения. 
Таблица 1. Динамика индекса Barthel на госпитальном этапе в обеих группах больных с ИИ

\begin{tabular}{c|c|c|c|c}
\hline \multirow{2}{*}{ Балл } & \multicolumn{2}{|c|}{ І группа $(n=30)$} & \multicolumn{2}{c}{ IІ группа $(n=31)$} \\
\cline { 1 - 5 } & Поступление & Выписка & Поступление & Выписка \\
\hline $0-5$ & 30 & 1 & 29 & 2 \\
\hline $6-10$ & - & 2 & 2 & 14 \\
\hline $11-15$ & - & 9 & - & 9 \\
\hline $16-20$ & - & 18 & - & 6
\end{tabular}

Пр им ечание. $n-$ количество пациентов.

Эта область является одной из важнейших зон нервно-сосудистой регуляции межполушарных связей. Расстояние от излучателя до кожи $5-10 \mathrm{~cm}$. Длительность процедуры $22.5 \mathrm{~min}$. Курс лечения 8-15 процедур в зависимости от динамики регресса неврологической симптоматики.

Процедуры с THz-излучением в I группе проводили и на этапах амбулаторно-поликлинической реабилитации: через 6, 12 и 24 месяца от начала заболевания в объеме от 6 до 10 процедур на курсе. Пациенты II группы за весь период наблюдения получали только фармакологические препараты в различных сочетаниях.

Для оценки динамики восстановления сознания (в реанимационном отделении) при его угнетении и регресса неврологической симптоматики использовались шкалы Rankin, Barthel и шкала NIHHS (National Institutes of Health Stroke Scale) [9].

B I группе, составляющий его контингент, в начальном периоде госпитализации был немного тяжелее, чем во II группе, о чем свидетельствовали следующие показатели: продолжительность угнетенного сознания в часах $-75.13 \pm 15.03$ против $31.03 \pm 7.65$ (критерий достоверности $p<0.001)$; длительность интубирования в сутках $-5.67 \pm 1.18$ против $1.74 \pm 0.51(p<0.01)$.

Сроки пребывания больных обеих групп в неврологическом отделении после их перевода из реаниматологического отделения, хотя и отличалась в цифровом выражении, однако статистически это отличие оказалась недостоверным, $22 \pm 2$ дня у пациентов I группы против $18 \pm 1$ дней у пациентов контроля $(p>0.05)$.

За период стационарного наблюдения летальных случаев в обеих группах не было.

Как для определения изначального уровня активности пациента, так и для проведения мониторинга с целью определения эффективности лечения был использован индекс Barthel, который основан на оценке 10 функций, колеблющихся по степени возможности их выполнения больным: от независимо выполняемых до полностью зависимых от посторонней помощи. Существует разработанная градация индекса Barthel в зависимости от физической активности пациента: суммарный балл от 0 до 5 соответствует полной зависимости больного от посторонней помощи, от 6 до 10 - умеренной зависимости, от 11 до 15 - легкой зависимости и от 16 до 20 - полной независимости в повседневной деятельности.

Из приведенных данных (табл. 1) следует, что пациенты обеих групп при поступлении по индексу Barthel были очень тяжелы и по сумме набранных баллов в большинстве своем не выходили за величину 5 баллов. К концу госпитального этапа в среднем у всех пациентов I группы количество баллов по индексу Barthel составило 15.8, а среди больных II группы - 11.4. При детальном рассмотрении пациенты I группы, получавшие к медикаментозной терапии дополнительно процедуры THz-воздействия, в 3 раза чаще имели более высокие оценки от 16 до 20 баллов по индексу Barthel, чем во II группе (18 пациентов против 6 соответственно).

К концу стационарного лечения среди пациентов I группы в 1.5 раза чаще, чем во II группе, были больные, которые при тестировании набирали более высокие баллы (от 1 до 3) по шкале Rankin, которая имеет градацию от 0 (без симптомов инсульта) до 5 (требуется постоянное медицинское внимание и уход). В среднем показатель по шкале Rankin среди пациентов I группы к окончанию срока госпитализации составил величину 1.97 балла, что свидетельствовало о появлении у больных способности справляться с собственными делами без посторонней помощи, но не выполнять пока еще некоторые прежние обязанности. В то же время во II группе индекс Rankin к концу госпитального этапа был несколько выше и составил в среднем величину 3.1 балла (табл. 2).

Представленная в табл. 3 динамика индекса NIHHS, который имеет градацию 0 (без симптомов инсульта)

Таблица 2. Динамика индекса Rankin на госпитальном этапе в обеих группах больных с ИИ

\begin{tabular}{c|c|c|c|c}
\hline \multirow{2}{*}{ Балл } & \multicolumn{2}{|c|}{ І группа $(n=30)$} & \multicolumn{2}{c}{ IІ группа $(n=31)$} \\
\cline { 1 - 5 } & Поступление & Выписка & Поступление & Выписка \\
\hline 0 & - & - & - & - \\
1 & - & 8 & - & 2 \\
2 & - & 14 & 1 & 5 \\
3 & - & 8 & 3 & 13 \\
4 & 6 & - & 18 & 10 \\
5 & 24 & - & 9 & 1
\end{tabular}

Таблица 3. Динамика индекса NIHHS на госпитальном этапе в обеих группах больных с ИИ

\begin{tabular}{r|c|c|c|c}
\hline \multirow{2}{*}{ Балл } & \multicolumn{2}{|c|}{ І группа $(n=30)$} & \multicolumn{2}{c}{ II группа $(n=31)$} \\
\cline { 1 - 5 } & Поступление & Выписка & Поступление & Выписка \\
\hline $0-10$ & 1 & 28 & 37 & 19 \\
$11-20$ & 2 & 2 & 10 & 12 \\
$21-30$ & 27 & - & 17 & -
\end{tabular}


Таблица 4. Сравнительная характеристика функционального состояния больных I и II групп на этапах наблюдения по данным комплексного тестирования

\begin{tabular}{|c|c|c|c|c|c|c|}
\hline \multirow{2}{*}{$\begin{array}{c}\text { Этап } \\
\text { наблюдения }\end{array}$} & \multicolumn{2}{|c|}{ Индекс Barthel } & \multicolumn{2}{|c|}{ Индекс Rankin } & \multicolumn{2}{|c|}{ Индекс NIHHS } \\
\hline & I группа & II группа & I группа & II группа & I группа & II группа \\
\hline \multirow{2}{*}{$\begin{array}{c}\text { При } \\
\text { поступлении }\end{array}$} & $0.20 \pm 0.15$ & $1.94 \pm 0.40$ & $4.8 \pm 0.0740$ & $4.13 \pm 0.13$ & $26.73 \pm 0.76$ & $18.94 \pm 0.95$ \\
\hline & \multicolumn{2}{|c|}{$t=4.16 ; p<0.001$} & \multicolumn{2}{|c|}{$t=4.95 ; p<0.001$} & \multicolumn{2}{|c|}{$t=4.84 ; p<0.001$} \\
\hline \multirow{2}{*}{$\begin{array}{c}\text { При } \\
\text { выписке }\end{array}$} & $15.80 \pm 0.74$ & $11.41 \pm 0.71$ & $2.00 \pm 0.025$ & $3.10 \pm 0.17$ & $6.37 \pm 0.49$ & $8.87 \pm 0.72$ \\
\hline & \multicolumn{2}{|c|}{$t=4.30 ; p<0.001$} & \multicolumn{2}{|c|}{$t=6.40 ; p<0.001$} & \multicolumn{2}{|c|}{$t=2.91 ; p<0.001$} \\
\hline \multirow{2}{*}{$\begin{array}{c}\text { Через } \\
6 \text { месяцев }\end{array}$} & $18.92 \pm 0.34$ & $14.37 \pm 0.72$ & $1.90 \pm 0.16$ & $3.00 \pm 0.14$ & $5.14 \pm 0.93$ & $6.67 \pm 0.77$ \\
\hline & \multicolumn{2}{|c|}{$t=5.15 ; p<0.001$} & \multicolumn{2}{|c|}{$t=5.13 ; p<0.001$} & \multicolumn{2}{|c|}{$t=1.00 ; p>0.05$} \\
\hline \multirow{2}{*}{ Через год } & $18.92 \pm 0.25$ & $14.6 p m 0.81$ & $1.67 \pm 0.14$ & $2.90 \pm 0.15$ & $2.83 \pm 0.39$ & $7.03 \pm 0.74$ \\
\hline & \multicolumn{2}{|c|}{$t=5.10 ; p<0.001$} & \multicolumn{2}{|c|}{$t=5.89 ; p<0.001$} & \multicolumn{2}{|c|}{$t=5.00 ; p<0.001$} \\
\hline \multirow{2}{*}{ Через 2 года } & $19.00 \pm 0.20$ & $15.32 \pm 0.65$ & $1.63 \pm 0.19$ & $2.96 \pm 0.17$ & $2.74 \pm 0.42$ & $6.96 \pm 0.17$ \\
\hline & \multicolumn{2}{|c|}{$t=5.38 ; p<0.001$} & \multicolumn{2}{|c|}{$t=5.16 ; p<0.001$} & \multicolumn{2}{|c|}{$t=4.91 ; p<0.001$} \\
\hline
\end{tabular}

до 21-30 (тяжелый инсульт), подтверждает сделанные выше выводы.

В табл. 4 представлено среднее арифметическое по каждой из шкал в I (фармакотерапия + PTHz-излучение) и II (только фармакотерапия) группах, величина $t$ критерия Уэлча и соответствующая этому критерию величина $p$, характеризующая степень статистической значимости различий.

На основании проведтнного исследования нами было отмечено, что в функциональном плане по шкалам NIHSS, Rankin и индексу Barthel, больные I группы на протяжении двухлетнего динамического наблюдения несколько превосходили пациентов II группы.

Тот факт, что у больных I группы индекс Barthel уже к моменту выписки из стационара приближался к своей максимальной отметке, еще не означал, что врачу, занимающемуся реабилитацией пациентов с ИИ, не над чем было работать.

К концу периода наблюдения в I группе инвалидность первой группы имел 1 пациент и 14 больных имели вторую группу инвалидности, в то время как во II группе на инвалидности второй группы было вдвое больше человек. Было также отмечено, что пациентам I группы с течением времени на фоне улучшения самочувствия уменьшали дозировки препаратов и 14 человек вернулись к прежней трудовой деятельности, в то время как во II группе такой тенденции в лекарственной терапии не наблюдалось и лишь два человека начали трудиться на прежней работе.

Более выраженный прогресс у пациентов I группы мог быть обусловлен (при прочих относительно равных условиях) более полным восстановлением функций организма на фоне медикаментозной терапии и под- ключения процедур THz-излучения, чем во II группе, получавших только лекарственную терапию.

Использование аппарата „ИК-Диполь“ оказалось эффективным у пациентов с ишемическим инсультом и после кардиохирургических операций со следующими осложнениями в послеоперационном периоде: сердечнососудистая и дыхательная недостаточность, психомоторное возбуждение, угнетенное сознание, гипертермия, нарушения функций тазовых органов, двигательные нарушения после ОНМК, нарушения сердечного ритма на фоне текущего инфаркта миокарда.

\section{Заключение}

Показано, что THz-излучение влияет на реакции метаболизма в организме человека в сочетании с управлением важнейшими биохимическими процессами. Развитие данного направления в практической медицине стимулировало разработку и развитие технологии получения компактных приемников и источников $\mathrm{THz}-$ и $\mathrm{GHz}-и з-$ лучения. Такие источники были реализованы в рамках планарной кремниевой нанотехнологии, которая обеспе-

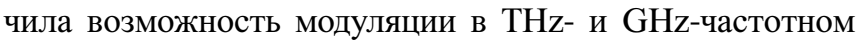
диапазоне вследствие встраивания микрорезонаторов в краевые каналы излучателей, представляющих собой сверхузкие кремниевых квантовые ямы на поверхности

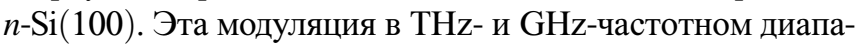
зоне способствовала эффективной терапии демиелинизирующих заболеваний центральной нервной системы.

\section{Финансирование}

Работа выполнялась в рамках программы исследований, запланированных в Физико-техническом институте 
им. А.Ф. Иоффе РАН и Национального медицинского исследовательского Центра им. В.А. Алмазова.

\section{Соблюдение этических стандартов}

Все процедуры, выполненные в исследовании с участием людей, соответствуют этическими стандартами институционального и/или национального комитета по исследовательской этике и Хельсинкской декларации 1964 года и ее последующим изменениям или сопоставимым нормам этики.

От каждого из включенных в исследование участников было получено информированное добровольное согласие.

\section{Конфликт интересов}

Авторы заявляют, что у них нет конфликта интересов.

\section{Список литературы}

[1] Fischer B.M., Walther M., Jepsen P. // Phys. Med. Biol. 2002. Vol. 47. P. 3807-3814.

[2] Плахова В.Б., Подзорова С.А., Мищенко И.В., Баграев Н.Т., Клячкин Л.Е., Маляренко А.М., Романов В.В., Крылов Б.В. // Сенсорные системы. 2003. Т. 17. Вып. 1. C. $24-31$.

[3] Rothman J.E., Orci L. // Sci. Amer. 1996. N 274. P. 70.

[4] Баграев Н.Т., Клячкин Л.Е., Маляренко А.М., Новиков Б.А. // Биотехносфера. 2015. № 5 (41). С. 55-70.

[5] Давыдов А.С. Биология и квантовая механика. Киев: Наукова думка, 1979. $296 \mathrm{c.}$

[6] Bagraev N.T., Grigoryev V.Yu., Klyachkin L.E., Malyarenko A.M., Mashkov V.A., Romanov V.V. // Low Temperature Phys. 2017. Vol. 43. N 1. P. 132-142.

[7] Louveau A., Smirnov I., Keyes J., Cornelison R.C., Kingsmore K.M., Contarino C., Onengut-Gumuscu $S$., Farber E., Raper D., Viar K.E., Powell R.D., Baker W., Dabhi N., Bai R., Cao R., Hu S., Rich S.S., Munson J.M., Lopes M.B., Overall C.C., Acton S.T., Kipnis J. // Center for Brain Immunology and Glia. School of Medicine. 2015. P. 1-4.

[8] Da Mesquita S., Louveau A., Vaccari A., Smirnov I., Cornelison R.C., Kingsmore K.M., Contarino C., OnengutGumuscu S., Farber E., Raper D., Viar K.E., Powell R.D., Baker W., Dabhi N., Bai R., Cao R., Hu S., Rich S.S., Munson J.M., Lopes M.B., Overall C.C., Acton S.T., Kipnis J. // Nature. 2018. Vol. 560. P. 185-191.

[9] Uyttenboogaart M., Stewart R.E., Vroomen P.C.A.J., De Keyser J., Luijckx G-E. // Stroke. 2005. Vol. 36. P. 1984-1987. 